\title{
GAMBARAN HIGIENE SANITASI PENGOLAHAN MAKANAN DI RUMAH MAKAN YANG ADA DI WILAYAH KERJA PUSKESMAS KOTA
}

\author{
Sakriani $^{1 \bowtie}$, Purnama Sidebang $^{2}$, \\ ${ }^{1}$ Poltekkes Kemenkes Ternate, Indonesia \\ ${ }^{1}$ sakrianijamaluddin@gmail.com
}

\begin{abstract}
Abstrak
Rumah makan adalah salah satu bangunan tempat-tempat umum dengan ruang lingkup kegiatannya menyediakan makanan dan minuman untuk umum. Oleh karena itu, rumah makan harus memenuhi persyaratan kebersihan dan kesehatan. Penelitian ini bertujuan untuk mengetahui gambaran higiene sanitasi rumah makan yang ada di wilayah kerja Puskesmas Kota. Penelitian ini merupakan penelitian deskriptif. Jumlah sampel pada penelitian ini sebanyak 31 rumah makan. Hasil penelitian menunjukkan bahwa pada variabel lokasi dan bangunan, fasilitas sanitasi, dapur, ruang makan dan gudang bahan makanan, bahan makanan dan makanan jadi, serta pengolahan makanan, paling banyak berisiko rendah masing-masing $51,6 \%$ dan yang berisiko tinggi masing-masing $48,4 \%$. Untuk variabel tempat penyimpanan bahan makanan dan makanan jadi $96,8 \%$ berisiko rendah dan 3,2\% berisiko tinggi penyajian makanan $45,2 \%$ berisiko rendah dan $54,8 \%$ berisiko tinggi. Peralatan $96,8 \%$ berisiko rendah dan $3,2 \%$ dan tenaga kerja $93,5 \%$ berisiko rendah dan $6,5 \%$ berisiko tinggi. Dari 31 rumah makan yang diteliti, 23 rumah makan $(74,2 \%)$ masuk kategori berisiko tinggi dan 8 rumah makan $(25,8 \%)$ masuk kategori risiko rendah. Disarankan bagi pemilik rumah makan agar higiene sanitasi penyajian makanan lebih diperhatikan khususnya cara penyajian makanan jadi supaya menggunakan alat yang bersih, cara membawa dan menyajikan makanan tertutup.
\end{abstract}

\begin{abstract}
Restaurant is one of the commercial public places that provides food and beverage for public. Therefore, restaurant must meet the clean and health standard. The aim of this study was to describe hygiene and sanitation of restaurant under Puskesmas Kota's working area. This was an observational study with descriptive design. 31 restaurants were involved as samples of the study. The result suggested that about $51,6 \%$ restaurant's location and building, sanitation facilities, kitchen, dining room and foodstuff storage, foodstuff and prepared food and food processing were categorized as low risk and $48,4 \%$ as high risk. About $96,8 \%$ of restaurant's foodstuff and food storage categorized as low risk and the rest as high risk. About $54,8 \%$ of restaurants sample had a high a risk food serving. It was $74,2 \%$ of 31 restaurants categorized as high risk. It could be suggested to restaurants owner to pay more attention, especially in food serving, use clean utensils and cutleries, use food cover when transport and serve them.
\end{abstract}

\section{Pendahuluan}

Undang-undang No. 36 tahun 2009 tentang kesehatan menyebutkan bahwa peningkatan dan pemantapan upaya kesehatan diselenggarakan melalui berbagai macam kegiatan, salah satunya adalah pengamanan makanan dan minuman. Upaya pengamanan makanan dan minuman akan lebih ditingkatkan untuk mendukung peningkatan dan pemantapan upaya kesehatan secara berhasil guna dan berdaya guna. Semua itu merupakan upaya untuk melindungi masyarakat dari makanan dan minuman yang tidak memenuhi persyaratan mutu (Depkes RI, 2009).

Salah satu masalah akibat makanan yang tidak memenuhi persyaratan mutu dapat mengganggu kesehatan di antaranya adalah keracunan makanan dan penyakit bawaan makanan. Keracunan makanan adalah suatu penyakit yang disebabkan mengkonsumsi makanan yang berbahaya atau terkontaminasi. Terjadinya penyakit karena makanan erat kaitannya dengan lingkungan yang digambarkan sebagai diagram V, yaitu penularan penyakit melalui fly (lalat), fingers (tangan), freld (tanah), dan food (makanan).

Banyaknya kasus keracunan baik yang diberitakan surat kabar maupun yang tidak terungkap dari gejala ringan, muntah-muntah , sampai berat yaitu kematian menunjukkan penanganan sanitasi yang masih kurang baik. Hal ini disebabkan karena pemahaman sanitasi yang masih kurang. Untuk itu peran sanitasi menjadi sangat penting sebagai upaya untuk mencegah kemungkinan tumbuh dan berkembangnya mikroba 
pembusuk dan patogen dalam makanan, minuman, peralatan dan bangunan yang dapat merusak pangan dan membahayakan manusia. (Handayani 2010).

Di Amerika serikat 25\% dari semua penyebaran penyakit melalui makanan, di sebabkan pengolah makanan yang terinfeksi dan higiene perorangan yang buruk (Maria, 2011). Kasus Keracunan pangan di Indonesia pada tahun 2011 disebabkan oleh pangan jasa boga 30 KLB (23.4 \%), Pangan olahan 16 KLB (12.50\%), pangan jajanan $16 \mathrm{KLB}(12.50 \%)$, dan lain-lain 8 KLB (6.25\%). Pada 2011 terjadi 128 KLB keracunan pangan di Indonesia. KLB keracunan pangan, pada 2012 paling banyak terjadi pada pangan jajanan, pangan jasa boga dan masakan rumah tangga, yaitu $66 \%$ dan mengalami peningkatan menjadi $76 \%$ pada 2013. (Kompas 2013). makanan masih menjadi penyebab tertinggi terjadinya keracunan berdasarkan insiden keracunan nasional, (BPOM,2013).

Data yang diperoleh dari Dinas Kesehatan Kota Ternate telah mencatat jumlah tempat pengolahan makanan dengan kriteria rumah makan dan restoran sebanyak 188 yang berada di 10 wilayah Puskesmas yaitu Kalumata, Kota, Gambesi, Mayau, Kalumpang, Siko, Jambula, Moti, Hiri dan Sulamadaha. Dari ke 10 Wilayah Puskesmas di atas jumlah yang paling banyak terdapat ruamah makan di wilayah kerja Puskesmas Kota sebanyak 55 Rumah Makan, 4 diantaranya telah dibina dan diperiksa serta dinyatakan laik sehat atau memenuhi syarat (Profil Dinkes Kota Ternate, 2017).

Berdasarkan uraian latar belakang diatas, maka peneliti tertarik untuk melakukan penelitian tentang Gambaran Higiene Sanitasi Pengolahan Makanan di Rumah Makan yang Ada di Wilayah kerja Puskesmas Kota, Kota Ternate.

\section{Metode}

Jenis penelitian ini adalah penelitian observasional dengan pendekatan deskriptif yang menggambarkan Higiene Sanitasi Pengolahan Makanan Di Rumah Makan di Wilayah Kerja Puskesmas Kota, Kota Ternate.

Populasi adalah seluruh rumah makan yang ada di Wilayah Kerja Puskesmas Kota tahun 2017 sejumlah 55 Rumah Makan, sedangkan sampel dalam penelitian ini adalah Rumah Makan yang bersedia saja di Wilayah Kerja Puskesmas Kota. Pengambilan sampel dalam penelitian ini menggunakan Sampling Jenuh. Alat pengumpul data yang digunakan dalam penelitian ini adalah modifikasi formulir RM.2. Sesuai KEPMEMKES RI No. 1098/MENKES/SK/VII/2003, pada variabel lokasi dan bangunan alat ukur yang digunakan untuk mengukur pencahayaan/penerangan adalah Lux meter, meteran untuk mengukur tinggi langitlangit dan ukuran ruang makan perkursi tamu.

\section{Hasil dan Pembahasan}

Variabel lokasi dan bangunan di wilayah kerja Puskesmas Kota Tahun 2017 dengan jumlah rumah makan sebanyak 31 yang dikategorikan resiko rendah sebanyak 16 rumah makan $(51,6 \%)$ dan yang dikategorikan resiko tinggi sebanyak 15 rumah makan $(48,4 \%)$. Variabel fasilitas sanitasi di wilayah kerja Puskesmas Kota Tahun 2017 dengan jumlah rumah makan sebanyak 31 yang dikategorikan resiko rendah sebanyak 16 rumah makan $(51,6 \%)$, dan yang dikategorikan resiko tinggi sebanyak 15 rumah makan $(48,4 \%)$. Variabel dapur, ruang makan dan gudang bahan makanan di wilayah kerja Puskesmas Kota Tahun 2017 dengan jumlah rumah makan sebanyak 31 yang dikategorikan resiko rendah sebanyak 16 rumah makan $(51,6 \%)$ dan yang dikategorikan resiko tinggi sebanyak 15 rumah makan $(48,4 \%)$.

Variabel bahan makanan dan makanan jadi di wilayah kerja Puskesmas Kota Tahun 2017 dengan jumlah rumah makan sebanyak 31 yang dikategorikan resiko rendah sebanyak 16 rumah makan $(51,6 \%)$ dan yang dikategorikan resiko tinggi sebanyak 15 rumah makan $(48,4 \%)$. Variabel pengolahan makanan di wilayah kerja Puskesmas Kota Tahun 2017 dengan jumlah rumah makan sebanyak 31 yang dikategorikan resiko rendah sebanyak 16 rumah makan $(51,6 \%)$ dan yang dikategorikan resiko tinggi sebanyak 15 rumah makan (48,4\%). Variabel tempat penyimpanan bahan makanan dan makanan jadi di wilayah kerja Puskesmas Kota Tahun 2017 dengan jumlah rumah makan sebanyak 31 yang dikategorikan resiko rendah sebanyak 30 rumah makan $(96,8 \%)$ dan yang dikategorikan resiko tinggi sebanyak 1 rumah makan $(3,2 \%)$.

Variabel penyajian makanan di wilayah kerja Puskesmas Kota Tahun 2017 dengan jumlah rumah makan sebanyak 31 yang dikategorikan resiko rendah sebanyak 14 rumah makan $(45,2 \%)$ dan yang dikategorikan resiko tinggi sebanyak 17 rumah makan $(54,8 \%)$. Variabel peralatan di wilayah kerja Puskesmas Kota Tahun 2017 dengan jumlah rumah makan sebanyak 31 yang dikategorikan resiko rendah sebanyak 30 rumah makan $(96,8 \%)$ dan yang dikategorikan resiko 
tinggi sebanyak 1 rumah makan $(3,2 \%)$. variabel tenega kerja di wilayah kerja Puskesmas Kota Tahun 2017 dengan jumlah rumah makan sebanyak 31 yang dikategorikan resiko rendah sebanyak 29 rumah makan $(93,5 \%)$ dan yang dikategorikan resiko tinggi sebanyak 2 rumah makan $(6,5 \%)$.

Tabel 1 menunjukkan bahwa dari 31 rumah makan yang diteliti sebanyak 8 rumah makan $(25,8 \%)$ memiliki skor $>548$ (berisiko rendah) dan skor 23 rumah makan $(74,2 \%)$ memiliki skor $<548$ (berisiko tinggi). Skor paling tinggi dengan kategori risiko rendah adalah 691,5 dan skor paling rendah adalah 387,5 dengan kategori risiko tinggi.
Tabel 1 Hasil Kategori Status Laik Rumah Makan di Wilayah Kerja Puskesmas Kota

\begin{tabular}{|c|c|c|c|c|}
\hline $\begin{array}{l}\text { No Rumah } \\
\text { Makan }\end{array}$ & $\begin{array}{l}\text { Total } \\
\text { Score }\end{array}$ & Kategori & $\mathbf{n}$ & $\%$ \\
\hline 14 & 387,5 & Risiko tinggi & \multirow{23}{*}{23} & \multirow{23}{*}{$\begin{array}{c}74,2 \\
\%\end{array}$} \\
\hline 2 & 409,5 & Risiko tinggi & & \\
\hline 19 & 421,5 & Risiko tinggi & & \\
\hline 24 & 428 & Risiko tinggi & & \\
\hline 26 & 436,5 & Risiko tinggi & & \\
\hline 3 & 446 & Risiko tinggi & & \\
\hline 10 & 449,5 & Risiko tinggi & & \\
\hline 18 & 451,5 & Risiko tinggi & & \\
\hline 7 & 452,5 & Risiko tinggi & & \\
\hline 20 & 458 & Risiko tinggi & & \\
\hline 21 & 461 & Risiko tinggi & & \\
\hline 30 & 477,5 & Risiko tinggi & & \\
\hline 8 & 478 & Risiko tinggi & & \\
\hline 25 & 478 & Risiko tinggi & & \\
\hline 4 & 482,5 & Risiko tinggi & & \\
\hline 28 & 490,5 & Risiko tinggi & & \\
\hline 11 & 509 & Risiko tinggi & & \\
\hline 31 & 510 & Risiko tinggi & & \\
\hline 29 & 512 & Risiko tinggi & & \\
\hline 1 & 535,5 & Risiko tinggi & & \\
\hline 16 & 535,5 & Risiko tinggi & & \\
\hline 23 & 542 & Risiko tinggi & & \\
\hline 15 & 542,5 & Risiko tinggi & & \\
\hline 22 & 557 & Risiko rendah & \multirow{8}{*}{8} & \multirow{8}{*}{$\begin{array}{c}25,8 \\
\%\end{array}$} \\
\hline 27 & 557 & Risiko rendah & & \\
\hline 5 & 597,5 & Risiko rendah & & \\
\hline 12 & 598,5 & Risiko rendah & & \\
\hline 17 & 598,5 & Risiko rendah & & \\
\hline 9 & 608,5 & Risiko rendah & & \\
\hline 13 & 668,5 & Risiko rendah & & \\
\hline 6 & 691,5 & Risiko rendah & & \\
\hline
\end{tabular}

Sumber data: Data primer

Berdasarkan total skor seluruh variabel penelitian dengan jumlah skor diperoleh hasil dari 31 rumah makan yang diperiksa lebih banyak

Jurnal Kesehatan Poltekkes Ternate, 9(1), 2016, pages 6 - 10 
memiliki skor risiko tinggi (total skor < 548) dibandingkan dengan yang berisiko rendah (total skor $\geq 548$ ).

Hasil penelitian ini sejalan dengan penelitian yang dilakukan pada rumah makan di Pasar Pinasunkulan Manado pada tahun 2014 menunjukkan bahwa masih terdapat 17 rumah makan yang belum memenuhi persyaratan (Misdar, 2014).

Sebagian rumah makan belum memenuhi syarat fasilitas sanitasi itu bisa dari air rumah makan yang kotor, tidak tersedia air yang bersih di tempat cuci tangan dan setiap lubang ventilasi tidak ada terali tikus dan kain kasa serangga. Sebagian besar rumah makan tidak memenuhi syarat Dapur, ruang makan dan gudang bahan makanan Karena keadaan dapur selalu kotor dan tidak ada kulkas, peralatan makan selalu kotor. Alat makan yang kotor dapat disebabkan oleh kondisi alat, apakah mudah dibersihkan atau tidak mudah dibersihkan.

Pengolahan bahan makanan menjadi makanan jadi adalah tahap utama dalam proses penyediaan makanan. Pengolahan bahan makanan yang diteliti meliputi tiga hal yaitu, cara menjamah makanan, tempat pengolahan, dan peralatan masak yang digunakan.

Tempat peragaan makanan makanan yang tidak mempunyai tutup serta memliki gudang makanan yang di dalamnya di campur bahan lain selain bahan makanan mejadi faktor dalam menentukan persyaratan higiene sanitasi suatu rumah makan. Selain itu, berdasarkan hasil penelitian Meikawati, dkk (2010) di RSJD Dr. Amino Gondohutomo Semarang, diketahui bahwa penjamah makanan masih mengabaikan praktek higiene dan sanitasi dalam mengolah makanan. Praktek higiene dan sanitasi yang kurang antara lain penjamah tidak menggunakan penutup kepala saat mengolah makanan $(70 \%)$ dan tempat alat masak tidak terbebas dari serangga dan debu (55\%). Hasil penelitian Marpaung (2012) mengungkapkan bahwa penggunaan alat pelindung diri (penutup kepala, sarung tangan, celemek dll) pada saat mengolah makanan dinilai mengganggu dalam melaksanakan pekerjan sebagai penjamah makanan.

Sanitasi ruang pengolahan makanan tidak hanya tentang kebersihan saja, namun meliputi luas lantai juga. Luas lantai ruang pengolahan makanan yang bebas dari peralatan minimal $2 \mathrm{~m}^{2}$ untuk setiap karyawan (Menteri Kesehatan Republik
Indonesia, 2011: 6). Luas ruangan tersebut sudah terpenuhi, penjamah makanan dapat bergerak dengan leluasa selama bekerja.

Pengangkutan makanan dan minuman adalah cara yang dilakukan pedagang untuk membawa makanan dan minuman kepada konsumen. Kondisi ini sangat memungkinkan terjadinya kontaminasi makanan, dan hinggapnya serangga pada makanan. Adanya kontaminasi ini sangat memungkinkan makanan menjadi tercemar dan mengandung bahan-bahan yang dapat membahayakan bagi kesehatan konsumen.

\section{Penutup}

Dari 31 rumah makan yang diperiksa lebih banyak memiliki skor risiko tinggi (total skor < 548) dibandingkan dengan yang berisiko rendah (total skor $\geq 548$ )

Disarankan bagi pemilik rumah makan agar higiene sanitasi penyajian makanan lebih diperhatikan khususnya cara penyajian makanan jadi supaya menggunakan alat yang bersih, cara membawa dan menyajikan makanan tertutup.

\section{Daftar Pustaka}

Agustina Febria. 2009. Higiene dan sanitasi pedagang makanan jajanan tradisional di lingkungan sekolah dasar di kelurahan demang lebar daun palembang tahun 2009.

http://eprints.unsri.ac.id/74/3/abstrak8.pdf di akses pada 25 April 2017

Cantika Iqdhana, dkk. 2016. Higiene penjamah makanan dan sanitasi pengelolaan makanan di instalasi gizi rumah sakit umum daerah gambiran kota kediri. File://c:/Users/DANDI/Download/78359556-1-SM.pdf.

Depkes RI, 2003. Keputusan Menteri Kesehatan RI No. 1098/Menkes/SK/VII/2003 Tentang Persyaratan Hygiene Sanitasi Rumah Makan dan Restoran, Jakarta.

Malango, L. M. 2012. Aspek Hygiene dan Sanitasi Makanan pada Rumah Makan di Terminal 42 Andalas kota Gorontalo. https://media.neliti.com/media/publication s/37215-ID-aspek-hygiene-sanitasimakanan-pada-rumah-makan-di-terminal42-andalas-kota-goro.pdf. 
Maria, Yosvita.2011. Pengetahuan dan Perilaku Higiene Tenaga Pengolah Makanan di Instalasi Gizi Rumah Sakit Umum daerah dr. Kanujoso Djatiwibowo Balikpapan. Eprints.undip.ac.id/32574/1/386 Yosvita Malaria G2C309009.pdf.Diakses pada tanggal 26 April 2017.

Naria, Evi. Higiene Sanitasi Makanan dan Minuman Jajanan di Kompleks USU, Medan. Universitas Sumatera Utara.

Novriyanti Isa, 2012. Studi Hygiene Sanitasi Pada Rumah Makan Di Wilayah Kampus Universitas Negeri Gorontalo. http://media.neliti.com/media/publications/3 723-ID-studi-hygiene-sanitasi-pada-rumahmakan-diwilayah-kampus-unuversitasnegeri-goro.pdf.

Sonia, Victa. Evaluasi Penerapan Higiene dan Sanitasi Penyelenggaraan Makanan di RSUD Sunan Kalijaga Kabupaten Demak Tahun 2013. Unnes Journal of Public Health: Volume 4, Nomor 2 Tahun 2015.

Susanna, Dewi dan Budi Hartono. 2003, Pementauan Kualitas Makanan Keroprak dan Gado-gado di Lingkungan Kampus UI Depok Melalui PemeriksaanBakteriologis.http;//journal.ui.a c.id/index.php/health/article/viewfile/39115.

Vitria, dkk. Hubungan Higiene Sanitasi dan Cara Pengolahan Mie Ayam dengan Angka Kuman di Kota Padang. Jurnal Kesehatan Masyarakat: Volume 7, No. 2 Tahun 2013. 